\title{
Human Papillomavirus-Related Penile Intraepithelial Neoplasia
}

National Cancer Institute

\section{Source}

National Cancer Institute. Human Papillomavirus-Related Penile Intraepithelial Neoplasia. NCI Thesaurus. Code C162541.

Intraepithelial neoplasia of the penis caused by human papillomavirus infection. 